\title{
The effects of accumulation of an environmentally relevant polychlorinated biphenyl mixture on cytochrome P450 and P-glycoprotein expressions in fetuses and pregnant rats
}

\author{
Patrizia Bonfanti ${ }^{\mathrm{a}, *, 1}$, Anita Colombo ${ }^{\mathrm{a}, 1}$, Sara Villa ${ }^{\mathrm{a}}$, Francesca Comelli ${ }^{\mathrm{b}}$, Barbara Costa ${ }^{\mathrm{b}}$, \\ Angela Santagostino ${ }^{a}$ \\ ${ }^{a}$ Department of Environmental Sciences, University of Milano-Bicocca, Piazza della Scienza 1, 20126 Milan, Italy \\ ${ }^{\mathrm{b}}$ Department of Biotechnology and Bioscience, University of Milano-Bicocca, Piazza della Scienza 2, 20126 Milan, Italy
}

\section{A R T I C L E I N F O}

\section{Article history}

Received 31 July 2008

Received in revised form 19 December 2008

Accepted 24 January 2009

Available online 4 March 2009

\section{Keywords:}

P-170 glycoprotein

Rat

PCB levels

Pregnancy

Fetus

CYP450

\begin{abstract}
A B S T R A C T
The aim of this study was to improve knowledge about transplacental transfer of an environmentally relevant PCB mixture by evaluating congener levels in livers and brains of rat dams and fetuses after maternal exposure, and correlating them to the levels of CYP450 and P-glycoprotein, involved in biotransformation and xenobiotics export, respectively. Pregnant dams were injected daily from gestation day (GD) 15 to 19 with $10 \mathrm{mg} \mathrm{kg}^{-1}$ of a reconstituted mixture (RM) composed of PCB138, 153, 180 and 126. Our data indicate that at GD20 RM is partitioned among maternal tissues, and that fetuses are not excluded from this distribution, evidencing a placental transfer of PCBs. Considering the ratio of maternal and fetal PCB concentrations based on lipid-weight, the amounts of congeners were 7-fold lower in fetal livers than in maternal livers and 25-30-fold higher in fetal brains than in maternal ones. Moreover, in dams the congeners were able to induce hepatic CYP450 response (total CYP450, CYP1A and CYP2B), but failed to increase P-170 expression, while in fetuses the constitutive expression of CYP450 and $\mathrm{P}-170$ was not induced by treatment. Pearson Product-Moment Correlation applied to treated group data suggests that PCB accumulation in fetal livers, but not in brains, depended principally on their mothers' intoxication pattern. On the whole, these results emphasize the maternal liver and the fetal brain as depot organs for PCB sequestration and their susceptibility towards PCB toxicological risk. Moreover they highlight the lack of a coordinated response between the investigated defence mechanism.
\end{abstract}

(c) 2009 Elsevier Ltd. All rights reserved.

\section{Introduction}

Polychlorinated biphenyls (PCBs) are a group of widespread persistent lipophilic environmental pollutants, that biomagnify through food chains (Skaare et al., 2000) and bioaccumulate in human tissues and breast milk (Wang et al., 2004).

Several studies have shown that in adult mammal females the mobilization of lipids from fat tissue during gestation and lactation, necessary to match the energy requirements of the mothers (Gallenberg and Vodicnik, 1997), frees toxic fat-soluble compounds into maternal blood circulation, which can reach fetuses or newborns, causing adverse health effects becoming evident in young, developing animals.

Since the lipid content of breast milk is high, it is generally believed that the highest level of offspring PCB exposure takes

\footnotetext{
* Corresponding author. Tel.: +39 026448 2920; fax: +39 0264482996 E-mail address: patrizia.bonfanti@unimib.it (P. Bonfanti).

1 These authors have equally contributed to the work.
}

place during lactation. Nevertheless Dekoning and Karmaus (2000), reviewing the literature, suggested that PCBs may be also capable to cross placenta to a greater extent than previously assumed.

This study was designed to improve knowledge about PCB placental transfer and to highlight the importance of in utero exposure to offspring, investigating PCB disposition in two selected maternal and fetal rat organs: the liver, considered a depot organ for polyhalogenated aromatic hydrocarbons (Chen et al., 2001) and the brain, for the neurotoxic implications associated with these compounds (Newland 2001; Kuriyama and Chahoud, 2004). Moreover, since data have demonstrated that PCB amounts in venous serum can be well predicted by the corresponding levels in placenta (Wang et al., 2004) we have included this organ in our investigation.

Since the pattern of PCB composition in technical mixtures differs markedly from that found in animal tissues and milk (McFarland and Clarke 1989), we focused our attention on a previously unstudied reconstituted mixture (RM) composed by 
selecting PCB138, PCB153 and PCB180, as environmentally relevant congeners in terms of abundance in biological matrices, and a dioxin-like congener, PCB126, generally detected in trace because of its very high toxicity. The first three congeners were present in the mixture at the same concentration in order to determine what fraction of the dose for each congener is then taken up and retained by the tissues considered. The treatment was carried out on pregnant dams from day 15 to day 19 of gestation, because it is known that fetal mass increases by 10 -fold during this period, thus determining an increase in the disposition of PCB from the maternal lipid reserves into the fetus. Moreover, the scarcity of studies on levels of different PCB congeners correlated to the state of biotransformation activities and to the expression of defence mechanisms during pregnancy led us to investigate the modulation of CYP450 and plasma membrane glycoprotein P-170 in gestational day 20 (GD20) placenta and maternal and fetal organs, in order to identify a toxicological profile of the tested mixture.

Indeed, PCB mixtures or individual congeners are agonists for several cellular and nuclear receptors and are effective mixed function oxidase system inducers. In particular PCB153 and 180 are phenobarbital type inducers (CYP2B isoforms), PCB126 is a 3methylcholantrene (3-MC) type inducer (CYP1A isoforms) while PCB138 is a mixed type inducer (McFarland and Clarke 1989). However, less is known about the interaction of PCBs with P-170, an energy dependent drug efflux transporter that prevents intracellular accumulation of a wide variety of structurally diverse substrates. P-170, originally seen in mammalian tumor cell lines, was later detected in intestinal epithelial cells, capillary endothelium of blood-brain, blood testis barrier and placenta trophoblast (Novotna et al., 2004) where it assumes a protective role and influences the pharmacokinetics of drugs (Lin and Yamazaki, 2003). Taking this into consideration, we examined the modulation of $\mathrm{P}-170$ protein levels to show a possible complementary and/or synergic action with CYP450 in PCB disposal.

The results obtained here can contribute to filling the gaps of systematic studies regarding the toxic properties of a PCB mixture during mammal development.

\section{Materials and methods}

\subsection{Chemicals}

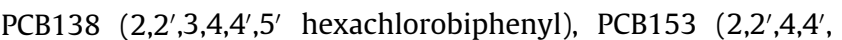

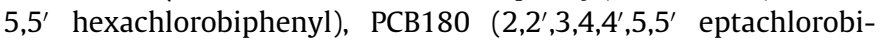
phenyl), PCB126 (3,3',4,4',5 pentachlorobiphenyl) (purity > 99\%), the standards of PCB30, 40, 128 and 141, used as internal or recovery standards were supplied by Dr. Esternstorfer (Germany). All solvents (residue analysis grade, Merck) were checked by gas chromatography (GC) before use. Sulphuric acid superpure for trace analysis was purchased from Carlo Erba (Italy). Pre packed florisil columns (Ultra-clean SPE Florisil $500 \mathrm{mg} / 4 \mathrm{~mL}$ ) were purchased by Alltech. Cellulose extraction thimbles for soxhlet were purchased by Albet (Spain). Protease inhibitor cocktail and the enhanced chemiluminescence (ECL) detection kit were purchased from Roche. The antibody C219 against P-170 and policlonal antibodies against CYP4501A1/2 and CYP4502B1/2 were purchased from Alexis and Chemicon, respectively. All other chemicals were obtained from Sigma.

\section{2. $P C B$ mixture}

The reconstituted PCB mixture (RM) was composed by PCB138, 153 and 180 at the same concentration (each representing one third of the total), while PCB126, normally present in trace in biological extracts, was added to the total mixture in a $1 / 10000$ ratio.
These congeners were dissolved in peanut oil (20 mg mixture $\mathrm{mL}^{-1}$ oil) in order to prepare a solution suitable for subcutaneous injection. The subcutaneous route was used to ensure complete absorption.

\subsection{Animals and treatment}

Time-pregnant Sprague-Dawley rats (Charles River, Italy) were obtained on GD2 (GD0 = day that sperm was detected in vaginal smear test). Upon arrival, rats were housed individually in clean polypropylene cages and maintained in a controlled environment with constant temperature $\left(21 \pm 1^{\circ} \mathrm{C}\right)$, humidity and a light/dark cycle $12 \mathrm{~h}$. All animals received a standard pellet diet and tap water ad libitum.

Pregnant rats were divided randomly into two groups, each consisting of 5 animals.

Group I: received subcutaneous injection of RM at a dose of $10 \mathrm{mg} \mathrm{kg}^{-1}$ body weight/die $\left(0.5 \mathrm{~mL} \mathrm{~kg}^{-1}\right)$. Group II: control rats were given plain peanut oil. The rats in each group received the RM or peanut oil (control) daily from GD15 to GD19. On GD20 all dams were sacrificed by decapitation and the fetuses removed by caesarean section. Maternal weights were monitored throughout gestation, while the fetus number from each litter and nest weight were recorded after caesarean section. Moreover, the fetus' sex was assessed by screening for the presence of the SRY gene in DNA on a brain fragment (Pravettoni et al., 2005). The average of fetus number obtained by each dam was $13.66 \pm 1.53$ for control group and $13.00 \pm 1.73$ for PCB treated group, while the sex ratio (Male/Female) was 1.2 for control and 0.94 for PCB treated group.

Livers and brains of both dams ( $n=5$ for each group) and fetuses ( $n=6$, randomly selected from the litter of each dam), as well as placentas were collected, split in three portions, snap frozen in liquid nitrogen and stored at $-80^{\circ} \mathrm{C}$ to estimate bioaccumulation, CYP450 content, CYP1A1 and CYP1A2, CYP2B1/2 and P-170 expression. Liver samples for total content of cytochrome P450 assay were processed immediately. Each measure was carried out on each single animal except for bioaccumulation analysis, where three fetal samples were pooled.

\subsection{Dose calculation}

Since this study is a part of an extensive investigation aimed to evaluate the $\mathrm{PCB}$ potential action to sex-steroid driven brain differentiation, which takes place in the last third of gestation (GD15) to weaning (post natal day 21) the treatment regimen scheduled a chronic administration of the RM with an initial loading dose over GD15-19, followed by maintenance doses given twice a week until weaning, providing an average RM daily intake of $4 \mathrm{mg} \mathrm{kg}^{-1}$ body weight.

\subsection{PCB quantification}

All samples (pools from three fetuses, $0.1 \mathrm{~g}$ total) were homogenized with sodium sulphate anhydrous, spiked with $25 \mathrm{ng}$ of PCB40 and 128 to check recovery efficiencies of methodology and Soxhlet extracted for $24 \mathrm{~h}$ in $n$-hexane. The extracts were reduced in a rotary evaporator under vacuum to $5 \mathrm{~mL}$, concentrated in a vial under a gentle nitrogen flow to $2 \mathrm{~mL}$, then an equal volume of sulphuric acid was added and vortexed for $5 \mathrm{~min}$. Hexane layers were pipetted off and charged on Ultra-clean SPE Florisil, which was eluted with $8 \mathrm{~mL}$ of ethylacetate: hexane $1: 1$ and $1 \mathrm{~mL}$ of hexane. The sample, reduced under gentle stream of nitrogen to $0.5 \mathrm{~mL}$, was transferred to $2 \mathrm{~mL} \mathrm{GC}$ vials. All extracts were further concentrated to facilitate solvent exchange to $25 \mu \mathrm{L}$ of dodecane containing two internal standards ( $\mathrm{PCB} 30$ and 141) for subsequent PCB quantification analysis. 
The extracts were analyzed by Gas Chromatography (gas chromatograph Agilent $6890 \mathrm{~N}$ equipped with a 50 mCPSil8 column $0.25 \mathrm{~mm}$ i.d. and 0,25 $\mu \mathrm{m}$ film thickness), coupled with Mass Selective Detector (Agilent MSD 5973N), positive electron impact (EI+) source in SIM mode. Samples $(2 \mu \mathrm{L})$ were injected by an Agilent 7683 auto injector, with the injection port at $250{ }^{\circ} \mathrm{C}$ in splitless mode. The carrier gas was helium, and the flow rate $1 \mathrm{~mL} \mathrm{~min}{ }^{-1}$.

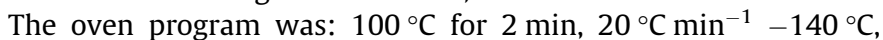
$4{ }^{\circ} \mathrm{C} \min ^{-1}-200{ }^{\circ} \mathrm{C}, 200{ }^{\circ} \mathrm{C}$ for $13 \mathrm{~min}, 4^{\circ} \mathrm{C} \min ^{-1}-300{ }^{\circ} \mathrm{C}$, $300{ }^{\circ} \mathrm{C}$ for $10 \mathrm{~min}$. The quadrupole MS was set in selected ion monitoring mode (SIM), with an EI+ source, a source temperature of $250{ }^{\circ} \mathrm{C}$, interface temperature of $280 \mathrm{C}$. The mean recovery of each analyte ranged between $70 \%$ and $110 \%$ and reproducibility was calculated by means of a triplicate analysis giving an overall $10 \%$ error. A series of procedural blanks were analyzed periodically. Reported values were blank corrected. Method detection limit was determined as the instrument detection limit of the lowest concentration standard of each analyte, which was $0.5 \mathrm{pg} \mu \mathrm{L}^{-1}$ for each congener. Analytical (instrument) variation is typically $<10 \%$ as measured by repeated injections of samples.

The lipid content of each sample was determined by evaporating the extract, obtained by $2 \mathrm{~h}$ ultrasonic extraction of a mixture of hexane-acetone, in an oven at $105^{\circ} \mathrm{C}$ for $1 \mathrm{~h}$. The percent lipids by dry weight were calculated by weighing the extracts evaporated.

\subsection{Microsome preparation for cytochrome P450 analysis}

Fragments of about $0.5 \mathrm{~g}$ from livers and brains of dams and fetuses were homogenized in ice-cold $0.15 \mathrm{M} \mathrm{KCl}(\mathrm{v}: \mathrm{w})$ and centrifuged at $9000 \mathrm{~g}$, at $4{ }^{\circ} \mathrm{C}$ for $10 \mathrm{~min}$. Supernatants were then ultra centrifuged at $100000 \mathrm{~g}$, at $4{ }^{\circ} \mathrm{C}$ for $1 \mathrm{~h}$ in order to obtain microsomal pellets which were stored at $-80^{\circ} \mathrm{C}$ until analyzed.

\subsection{Spectrophotometric cytochrome P450 assay}

The hepatic total content of cytochrome P450 was determined spectrophotometrically in fresh liver samples, according to Omura and Sato (1964). The specific content of cytochrome P450 (nmol mg ${ }^{-1}$ protein) was calculated according to Lambert-Beer's Law using an extinction coefficient value for cytochrome P450 of $0.091 \mathrm{nM} \mathrm{cm}^{-1}$.

\subsection{Total membrane protein preparation for $P-170$ analysis}

Total membrane proteins from placentas as well as from livers and brains both of dams and fetuses were obtained according to Novotna et al. (2004) with minor modifications. Briefly, the frozen organs were weighed and homogenized with a motor driven Potter-Elvehjem homogenizer in ice-cold buffer $(1: 10 \mathrm{w} / \mathrm{v})(\mathrm{pH}$ 7.4) containing $250 \mathrm{mM}$ sucrose, $10 \mathrm{mM}$ Tris, $5 \mathrm{mM}$ EDTA and protease inhibitor cocktail. The homogenates were centrifuged at $10000 \mathrm{~g}$ for $10 \mathrm{~min}$ at $4{ }^{\circ} \mathrm{C}$ and the supernatants again centrifuged at $36000 \mathrm{~g}$ for $70 \mathrm{~min}$ at $4{ }^{\circ} \mathrm{C}$. The pellets were suspended in a small volume of homogenization buffer and stored at $-80^{\circ} \mathrm{C}$.

\subsection{SDS-PAGE and immunoblotting}

Aliquots of each sample were used for protein determination according to Bradford (1976). Plasma membrane proteins for P-170 (50 $\mu \mathrm{g} /$ well) and microsomal proteins for CYP1A1, CYP1A2 and CYP2B1/2 isoforms ( $40 \mu \mathrm{g} /$ well for livers and $100 \mu \mathrm{g} /$ well for brains), obtained from individual dams ( $n=5$ for both control and PCB treatment) and fetuses ( $n=6$ randomly selected from the litter of each dam), were mixed with sample buffer, loaded onto $7.5 \%$ or $10 \%$ SDS-polyacrylamide gel, respectively, and run electrophoretically. The proteins were transferred overnight $(\mathrm{O} / \mathrm{N})$ to nitrocellulose membranes and the blots were probed with appropriate antibodies. Briefly, blots were blocked $\mathrm{O} / \mathrm{N}$ at $4{ }^{\circ} \mathrm{C}$ with PBS-BSA 5\% and incubated for $2 \mathrm{~h}$ with antibodies against P-170 $(1: 40)$ and CYP1A1/2 or CYP2B1/2 (1:1000) for hepatic microsomes, and with an $\mathrm{O} / \mathrm{N}$ incubation at $4{ }^{\circ} \mathrm{C}$ for brain microsomes.

Detection of P-170 was achieved by using an alkaline phosphatase-conjugated secondary antibody (1:30000) with nitro blue tetrazolium and 5-bromo-4-chloro-3-indolyl phosphate as substrates for the phosphatase reaction. Cytochrome P450 isoforms were detected with an enhanced chemiluminescence (ECL) detection kit after $1 \mathrm{~h}$ incubation with the secondary antibody (anti-rabbit IgG, peroxidase linked F(ab')2 fragment, 1:1500).

At least three independent blots for each liver and brain sample (dams $n=5$ for each group and fetuses $n=6$ for each dam) were performed and the quantification of the signal was analyzed using computerized densitometry of scanned images (Biorad, Quantity One). Any change in protein levels was expressed as percentage over control.

\subsection{Statistical analysis}

Data were statistically analyzed by the Statgraphics plus program for Windows (version 5.1, MD, USA) or by GrephPad Prism 4. ANOVA and the Duncan Multiple Range test was applied when normality and homogeneity of variance were satisfied. Data which did not conform to the assumptions, were analyzed by the Kruskal-Wallis test (a test for differences of location in ranked data grouped by single classification) and the Dunns test for comparing pair of groups as post test.

In order to determine the relationship among pairs of variables the Pearson Product-Moment Correlation Coefficient was computed. In order to establish and estimate the relationship between kinetic parameters in mothers and fetuses and in placenta, Product-Moment Correlation Coefficients were calculated for 10 parameters describing the fetuses of the mothers exposed to PCB RM. In particular, the parameters considered were: total PCB content expressed as the sum of PCB congeners in fetal and maternal livers and brains, and in placenta, cytochrome $\mathrm{P} 450$ hepatic total content both in maternal and fetal livers, P-170 expression in fetal and maternal livers and in placenta.

\section{Results}

\subsection{Maternal and fetal outcome data}

Administration of PCB RM from GD15 to GD19 to time pregnant rats has not produced any signs of maternal toxicity as well as statistically significant changes in body weight gain. Amount of resorption, litter size, sex ratio and fetuses' GD20 body weight were not at all affected.

\subsection{Levels of $P C B$ congeners in maternal and fetal tissues}

PCB levels were analyzed in livers and brains of dams and fetuses at GD20, and in placentas. None of the dosed congeners were detected in any batches of sample blanks, representing the level of reagent and laboratory contamination, as well as in all control samples. Detectable amounts of PCB138, PCB153 and PCB180 were identified in all maternal and fetal samples, while PCB126 concentration was less than the detection limit in all samples. Since adult lipid content is greater than that of fetuses, both wet weight and lipid normalized PCB values were used in our subsequent analysis.

In GD20 pregnant rats, the levels of PCB congeners detected in livers were approximately 55-fold higher than in brains if based 

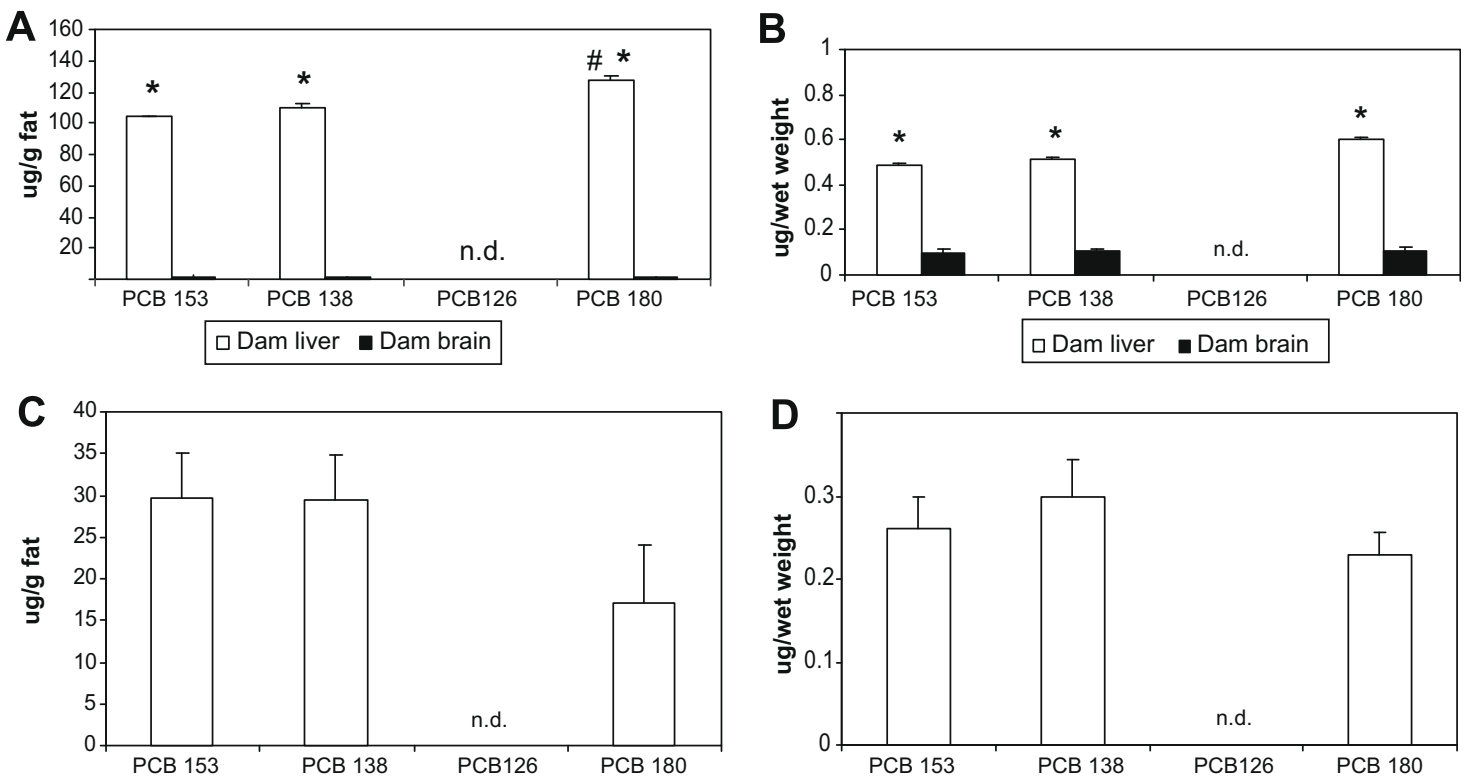

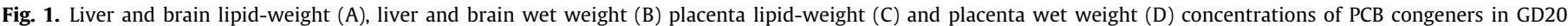

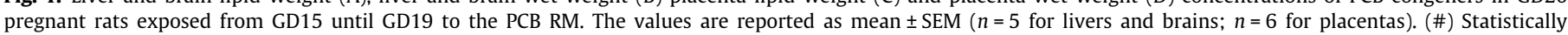

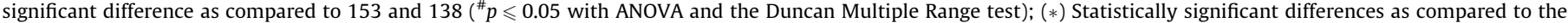
brain ( $p \leqslant 0.05$ with ANOVA and the Duncan Multiple Range test); (n.d.) not detected.
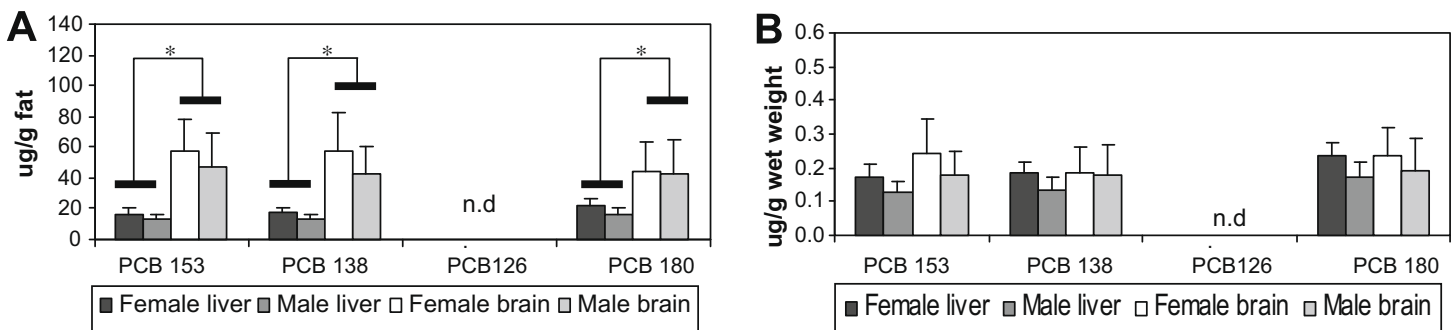

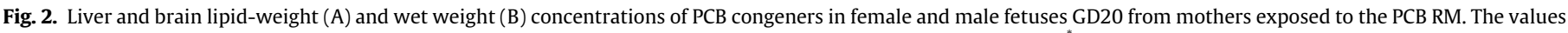

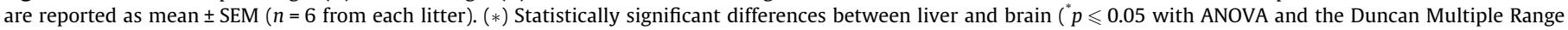
test); (n.d.) not detected.

on lipid-weight (Fig. 1A), or about 5-fold higher if referred to wet weight (Fig. 1B). In both cases, statistical analysis showed that the PCB levels measured in livers are significantly higher than those in brains $(p \leqslant 0.05)$. Moreover, while in brains the three congeners detected accumulate to the same extent, in liver PCB180 levels are statistically higher than those of PCB153 and $138(p \leqslant 0.05)$.

Also placenta demonstrated a moderate capability in PCB accumulation (Fig. 1C and D), evidencing PCB levels only about 2-fold lower than maternal livers if referred to the wet weight, (Fig. 1B) and 4 -fold lower if referred to the lipid-weight (Fig. 1A). As in brains, the levels of the three congeners in placenta were not statistically different. The concentration and the distribution pattern of the different congeners in fetal compartments were different from that in dams. Indeed, if compared to the fetal liver, the accumulation of $\mathrm{PCB}$ congeners in fetal brains was similar when normalized to wet weight (Fig. 2B) or 3-fold higher based on lipid-weight, with a statistically significant difference (Fig. 2A). Moreover, even if the PCB levels in females are slightly higher than in males, this difference is not significant.

In contrast to the maternal liver PCB pattern, the little difference between PCB180 and the other two congeners in fetal livers was statistically insignificant.
Considering the ratio of maternal and fetal PCB concentrations based on lipid-weight, the amounts of the compounds were approximately 7-fold lower in fetal than in maternal livers and 25-30-fold higher in fetuses than in maternal brains.

If the average ratios of $\mathrm{PCB}$ levels in maternal and fetal tissues relative to those in placenta are considered, it appears evident that only the ratio of maternal liver levels relative to those in placenta tended to be greater than one (Fig. 3), whereas the ratio of the lev-

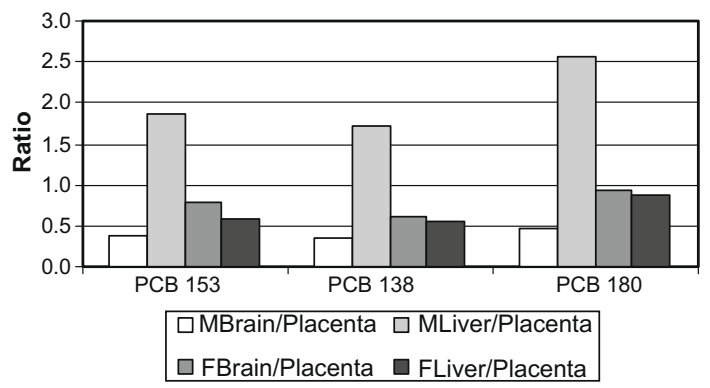

Fig. 3. Ratios of PCB levels in maternal livers (MLivers), maternal brains (MBrains), fetal livers (FLivers) and fetal brains (Brains) relative to the levels in placenta. 
A

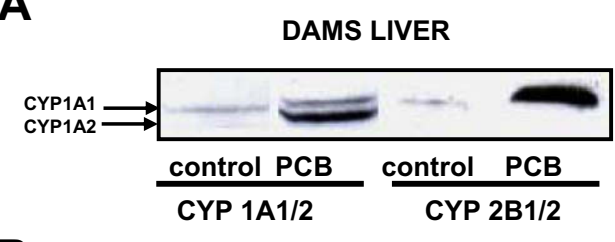

B

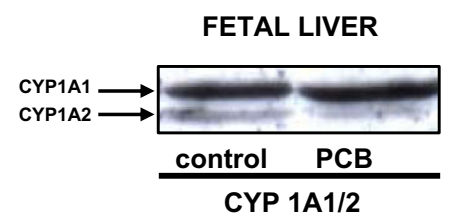

C

PLACENTA
DAMS BRAIN

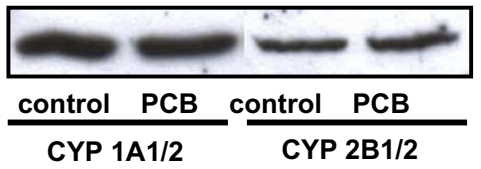

FETAL BRAIN

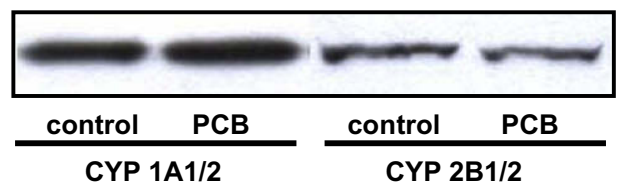

DAMS LIVER

FETAL LIVER

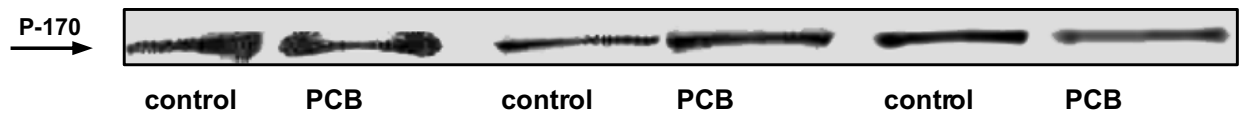

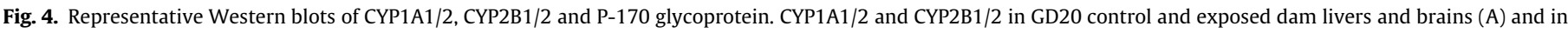

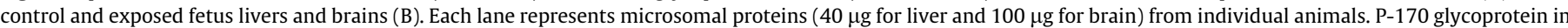

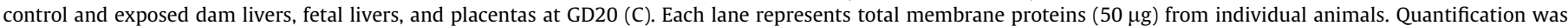

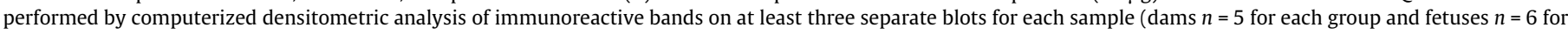
each dam) to account for blot-to-blot variation.

els in maternal brains and in fetal tissues relative to placenta tended to be less than one.

\subsection{Total cytochrome P450 content and CYP isoform expression in maternal and fetal tissues}

The treatment during gestation elicited a statistically significant ( $p<0.001$ with Kruskal-Wallis test and the Dunns test) increase of $78 \%$ in mothers' hepatic P450 total levels, while in fetuses no increment was detected, although higher levels of basal P450 content were found in fetuses' livers in comparison to the mothers $\left(9.8 \pm 0.13 \mathrm{pmol} \mathrm{mg}^{-1}\right.$ proteins in fetuses versus $2.7 \pm 0.39$ pmol $\mathrm{mg}^{-1}$ proteins in mothers).

Western blot analysis showed a PCB-inducible expressions of both isoforms of CYP1A in all dam livers but only constitutive expression of CYP1A2 at the protein level of $40 \mu \mathrm{g}$; moreover a single constitutive and $\mathrm{PCB}$-induced CYP2B expression was identified (Fig. 4A). The densitometric analysis (data not shown), demonstrated that this statistically significant increase of CYP1A2 and CYP2B in maternal livers ( $p<0.01$ with Kruskal-Wallis test and Dunns test) is equal to $102 \% \pm 0.09$ and $310 \% \pm 5.33$ over control, respectively. In brains of control dams a single band of CYP1A and CYP2B expression achieved detectable levels at $100 \mu \mathrm{g}$ per lane, that was not incremented in PCB RM induced dams (Fig. 4A).

Fetal livers ( $40 \mu \mathrm{g}$ per well) from mothers exposed to PCB exhibit, both CYP1A1 and CYP1A2 isoforms that resulted uninduced as compared to controls, while no CYP2B expression was detected in control, or in fetal livers from exposed dams (Fig. 4B).

Differently from livers, constitutive protein levels of both CYP1A1/2 and CYP2B1/2 were evidenced at $100 \mu \mathrm{g}$ per lane in fetal brains, but these levels were not induced by treatment with PCBs (Fig. 4B).

\section{4. $P$-170 expression in maternal and fetal tissues}

An intense immunoreactive protein band with an apparent Mw of $170 \mathrm{KDa}$ was seen at $50 \mu \mathrm{g}$ per well in all control placentas and both in dam and fetus livers. Densitometric analysis (data not shown), demonstrated that these basal levels were not induced in tissues from PCB exposed animals (Fig. 4C). No detectable bands were evidenced in whole brain membranes.

\subsection{Relationships between maternal and fetal $P C B$ variables}

In order to establish and estimate the relationship between kinetic parameters in mothers and fetuses and in placenta, ProductMoment Correlation Coefficients were calculated for 10 parameters describing the fetuses of the mothers exposed to PCB RM. In particular, the parameters considered were: total PCB content expressed as the sum of $\mathrm{PCB}$ congeners in fetal and maternal livers and brains, and in placenta, P-170 and P450 expression both in maternal and fetal livers, and in placenta.

Table 1 displays the correlation analysis results between each pair of the aforementioned parameters, demonstrating that P-170 expression in placenta negatively influences both the PCB content in this organ and the CYP450 expression in fetal livers. Moreover, it is noteworthy that PCB accumulation in brains was not positively or negatively influenced by any considered parameter, while in fetal livers it depended principally on their mother's intoxication pattern and was positively correlated with PCB contents in maternal livers and brains as well as with P450 expression in maternal livers. PCB accumulation in fetal livers was however negatively correlated with P-170 expression in maternal livers.

\section{Discussion}

In this study the transplacental transfer of a PCB RM was investigated, evaluating the levels of congeners following maternal exposure from GD15 to GD20 in relevant maternal and fetal tissues and correlating them to the state of biotransformation systems and the expression of P-170. A mixture of congeners of highest concern as environmental contaminants in relation to their potential toxicity, frequency of occurrence and abundance in biological matrices (McFarland and Clarke, 1989), was preferred over single congeners or technical mixtures to achieve a more realistic exposure scenario. Even if the equal concentration of PCBs 180, 153 and 138 in the mixture does not mimic environmental human tissue levels, where 
Table 1

Pearson Product-Moment Correlations between each pairs of reported 10 variables in treated samples.

\begin{tabular}{|c|c|c|c|c|c|c|c|c|c|}
\hline & $\begin{array}{l}\text { Versus mother } \\
\text { liver PCB }\end{array}$ & $\begin{array}{l}\text { Versus mother } \\
\text { brain PCB }\end{array}$ & $\begin{array}{l}\text { Versus mother } \\
\text { liver P450 }\end{array}$ & $\begin{array}{l}\text { Versus mother } \\
\text { liver P-170 }\end{array}$ & $\begin{array}{l}\text { Versus } \\
\text { placental } \\
\text { P-170 }\end{array}$ & $\begin{array}{l}\text { Versus fetal } \\
\text { liver PCB }\end{array}$ & $\begin{array}{l}\text { Versus fetal } \\
\text { brain PCB }\end{array}$ & $\begin{array}{l}\text { Versus fetal } \\
\text { liver P450 }\end{array}$ & $\begin{array}{l}\text { Versus fetal } \\
\text { liver P-170 }\end{array}$ \\
\hline $\begin{array}{l}\text { Placental } \\
\text { PCB }\end{array}$ & $-0.3202(0.4009)(9)$ & $-0.1384(0.7225)(9)$ & $-0.3424(0.3670)(9)$ & $0.3632(0.3367)(9)$ & $-0.7722(0.0147)(9)$ & $-0.2709(0.4808)(9)$ & $0.2963(0.4388)(9)$ & $0.6334(0.0671)(9)$ & $\begin{array}{l}0.4099 \\
(0.2732)(9)\end{array}$ \\
\hline $\begin{array}{l}\text { Mother } \\
\text { liver PCB }\end{array}$ & - & $0.8696(0.3288)(5)$ & $0.9966(0.0524)(16)$ & $-0.9858(0.1072)(16)$ & $0.4112(0.1278)(15)$ & $0.5739(0.0201)(16)$ & $-0.2782(0.2967)(16)$ & $-0.3676(0.1777)(15)$ & $\begin{array}{l}0.0121 \\
(0.9657)(15)\end{array}$ \\
\hline $\begin{array}{l}\text { Mother } \\
\text { brain PCB }\end{array}$ & & - & $0.8260(0.3812)(5)$ & $-0.7745(0.4360)(5)$ & $0.4202(0.1189)(15)$ & $\mathbf{0 . 4 9 8 0}(\mathbf{0 . 0 4 9 6 ) ( 1 6 )}$ & $-0.3468(0.1881)(16)$ & $-0.3035(0.2715)(15)$ & $\begin{array}{l}0.1350 \\
(0.6314)(15)\end{array}$ \\
\hline $\begin{array}{l}\text { Mother } \\
\quad \text { liver P450 }\end{array}$ & & & - & $-0.9963(0.0548)(5)$ & $0.3994(0.1403)(15)$ & $0.5721(0.0206)(16)$ & $-0.2604(0.3301)(16)$ & $-0.3690(0.1759)(15)$ & $\begin{array}{l}-0.0086 \\
(0.9757)(15)\end{array}$ \\
\hline $\begin{array}{l}\text { Mother } \\
\quad \text { liver P-170 }\end{array}$ & & & & - & $-0.3841(0.1575)(15)$ & $-0.5663(0.0222)(16)$ & $0.2401(0.3705)(16)$ & $0.3678(0.1774)(15)$ & $\begin{array}{l}0.0303 \\
(0.9147)(15)\end{array}$ \\
\hline $\begin{array}{r}\text { Placental } \\
\text { P-170 }\end{array}$ & & & & & - & $0.3395(0.2157)(15)$ & $-0.4198(0.1193)(15)$ & $-0.6470(0.0091)(15)$ & $\begin{array}{l}-0.3155 \\
(0.2521)(15)\end{array}$ \\
\hline $\begin{array}{l}\text { Fetal } \\
\quad \text { liver PCB }\end{array}$ & & & & & & - & $0.2807(0.2923)(16)$ & $-0.1984(0.4784)(15)$ & $\begin{array}{l}-0.1055 \\
(0.7084)(15)\end{array}$ \\
\hline $\begin{array}{l}\text { Fetal } \\
\quad \text { brain PCB }\end{array}$ & & & & & & & - & $-0.3676(0.1777)(15)$ & $\begin{array}{l}0.0121 \\
(0.9657)(15)\end{array}$ \\
\hline Fetal liver P450 & & & & & & & & - & $\begin{array}{l}-0.0002 \\
(0.9994)(15)\end{array}$ \\
\hline $\begin{array}{l}\text { Fetal liver } \\
\text { P-170 }\end{array}$ & & & & & & & & & - \\
\hline
\end{tabular}

P-170

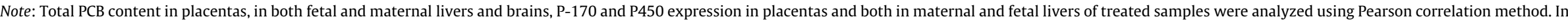

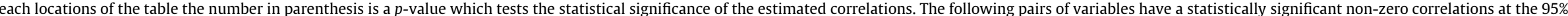

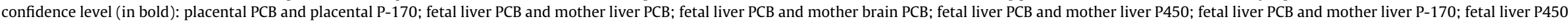

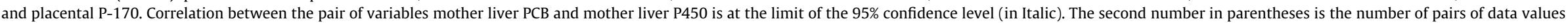
used to compute each coefficient. 
PCB153 is usually the dominant congener, we have chosen this approach to evidence a possible selective accumulation of the three congeners. Our data indicate that the PCBs are partitioned among the maternal tissues considered without a selective accumulation. In brains and in placenta the pattern of sequestration appears uncorrelated to the physical-chemical PCB properties, while in maternal livers, the levels of PCB congeners were correlated with their $\log$ Octanol-Water Partition Coefficient $\left(\log K_{\mathrm{ow}} 6.78\right.$ for PCB138, 6.73 for PCB153 and 7.14 for PCB180) (Ballschmiter et al., 2005) with a statistically significant accumulation of PCB180 in comparison with PCBs 153 and 138. Fetuses are not excluded from maternal PCB disposition, confirming that a clear placental transfer of these compounds occurs. This is consistent with a restricted protection towards these relatively small and high lipophilic molecules provided by the placenta (Lyche et al., 2004). As suggested by Koppe et al. (1992) in humans $10-20 \%$ of fetal fatty acids have maternal origin and PCBs may cross the placenta bound to them because of their fat solubility. Nevertheless, assuming that PCB levels in placenta correlate with those circulating in maternal blood as previously established (Wang et al., 2004; Chao et al., 2007), our study demonstrates that fetal tissues are able to accumulate PCBs to a lower extent than placenta. Conversely in dams, the livers, but not the brains, show higher levels of PCBs compared to placentas and this points out a hepatic sequestration capability. This retention could be related to an increase of maternal liver triglyceride concentration resulting from the adaptation of maternal lipid metabolism required for fetal growth (Cunnane and Armstrong, 1990). In addition the liver has an elevated metabolism and a high blood flow rate, which makes it a depot organ for PCBs (deJongh et al., 1993). The concept of the liver as a "depot organ" for different halogenated compounds has been described by Diliberto et al. (1999) and Chen et al. (2001), who have shown that TCDD and dioxin-like congeners, such as PCB126, induce besides CYP1A1, CYP1A2, an isoform able to bind and sequester these compounds in livers. In our study, basing on the strong induction of CYP1A1/2 in maternal livers, one can infer that PCB126 reaches the maternal liver, as shown by induction of CYP1A1/2, although the analytical method was not sufficiently sensitive to quantify it. Nevertheless it cannot be excluded that CYP1A1/2 expression was induced by the contribution of the other congeners tested. A very high response was evidenced also for CYP2B isoforms and CYP450 total content indicating that in dams the PCB RM induces an active hepatic metabolic state that might produce the biological character to potentially increase the risk of procarcinogen bioactivation in mother and consequently in offspring (Wakui et al, 2006). Nevertheless, it is important to underline that this risk is referred to high doses of PCBs, whereas at lower environmental levels CYP induction would be minimal. In spite of the high dose tested, in fetuses the constitutive CYP1A1/2 levels were not transplacentally induced by $\mathrm{PCB}$ treatment, whereas for CYP2B no protein bands were seen in control or exposed fetuses. This result confirms the lack or low expression in rat fetuses of many CYP450 isoforms detected in adults, as reported by Czekaj et al. (2005). Nevertheless, whether CYP450 gene regulatory mechanisms are present in fetal tissues remains controversial. Pineau et al. (1991) showed that CYP1A1/2 mRNAs and proteins were not expressed in livers of untreated rodent fetuses, but several studies have established that CYP1A enzymes can be induced transplacentally in fetal rat livers by potent inducers such as TCDD (Bell et al., 2007), PCBs and 3-MC (Borlakoglu et al., 1993). Taking this into consideration, it can be hypothesized that the lack of CYP1A response in fetal livers is not ascribable to the inherent incompetence of fetal tissues to respond to inducers such as PCB126, but it seems most likely that PCB126 does not reach the fetus at significant levels. The same explanation could be argued for the other three congeners, that were present in fetal livers in amounts 7-fold lower than in maternal livers. The limited bioavailability for PCB126 could be related to the strongly induced CYP1A2 isoform, capable of anchoring this congener by sequestering it in maternal livers as reported by Dragin et al. (2006) and Bell et al. (2007). Instead for PCB153, 138 and 180 , a dissimilar disposition occurs in fetuses compared to the mothers as the PCB levels in fetal brains are higher in comparison to those in livers when normalized to lipid-weight. This data is highly relevant considering that a number of studies have reported negative associations between prenatal PCB exposure and neurodevelopmental disturbances (Kuriyama and Chahoud, 2004).

In terms of CYP450 expression, both maternal and fetal brains appear positive for one of the two isoforms of CYP1A and CYP2B, nevertheless, the highlighted constitutive levels were not induced in response to PCBs measured in these organs probably because of the low levels of congeners detected, maybe below the inducibility threshold. Although the complete spectrum of specific CYP isoform expression in brains has not yet been defined, it is known that CYP1A1 is the principal constitutively expressed isoform in extra hepatic organs, but inducible in the liver as well as extrahepatic tissues, as opposed to CYP1A2, which is generally recognized as a predominantly hepatic in both constitutive and inducible expression.

However, the expression of CYP450 in brains suggests that the CYP-dependent metabolism in this organ may have important toxicological implications and may result in complex drug-chemical interactions, with potentially severe effects on the central nervous system.

Many authors have considered the role of membrane-bound cellular drug transporters and their effect on the pharmacokinetic behaviour of compounds. In particular P-170, one of these transporters, is considered a gatekeeper in placenta and blood-brain barrier (BBB) where it prevents xenobiotic release to the fetus and to the central nervous system, respectively (Tampal et al., 2003; Novotna et al., 2004). We investigated the expression of P170 in search of evidence of a modulation in its protein levels coordinated to CYP450 response. Our results demonstrate that maternal and fetal livers, as well as placenta, are equipped with constitutive levels of P-170. Unfortunately P-170 detection in brains failed, probably because of the scarcity of samples that did not allow us to obtain enriched fractions of luminal membranes. The PCB congeners used here do not co-induce P-170 as previously demonstrated for many other prototypical inducers of specific CYP450 isoforms (Fardel et al., 1996; Colombo et al., 2003). Basing on these experiments, it is impossible to draw a conclusion about the role of $\mathrm{P}-170$ in protection of maternal and fetal organs from exposure to PCBs. Concerning this aspect, studies performed by Tampal et al. (2003) have demonstrated that PCBs are able to bind this glycoprotein, and this could influence PCB disposition. Indeed Pearson Product-Moment Correlation, applied to data obtained in the treated group, suggests that the levels of this defence mechanism in maternal livers are negatively correlated with PCB accumulation in fetal livers.

In conclusion the present study documented that mammalian offspring are not completely protected from exposure to PCBs by placental barrier and that PCB accumulation in fetuses depends principally on the mothers' intoxication pattern. Nevertheless the levels of PCBs reaching fetus are not sufficient to induce CYP protein expression, even at the high dose administered to the mother. In contrast in treated dams the active hepatic metabolic state, due to over expression of CYP450, can potentially increase procarcinogen bioactivation risk but also detoxify other chemicals. Moreover the relatively high concentration of PCBs in fetal brains place this organ at more elevated risk of PCB toxicity in comparison with livers. 


\section{Acknowledgements}

This work was supported by a grant from the Italian Ministry of University and Research (MIUR) through the project PRIN 20042006. The authors thank Dr. Federica Orsi for technical assistance and Dr. Susan Campbell for language and style revision.

\section{References}

Ballschmiter, K., Klingler, D., Ellinger, S., Hackenberg, R., 2005. High-resolution gas chromatography retention data as a basis for estimation of the octanol-water distribution coefficients $\left(K_{\mathrm{ow}}\right)$ of $\mathrm{PCB}$ : the effect of experimental conditions. Anal. Bioanal. Chem. 382, 1859-1870.

Bell, D.R., Clode, S., Fan, M.Q., Fernandes, A., Foster, P.M.D., Jiang, T., Loizou, G MacNicoll, A., Miller, B.G., Rose, M., Tran, L., White, S., 2007. Relationships between tissue levels of 2,3,7,8-tetrachlorodibenzo-p-dioxin (TCDD), mRNAs, and toxicity in the developing male Wistar(Han) rat. Toxicol. Sci. 99, 591-604.

Borlakoglu, J.T., Scott, A., Henderson, C., Wolf, C., 1993. Transplacental transfer of polychlorinated biphenyls induces simultaneously the expression of P450 isoenzymes and the protooncogenes c-Ha.ras and c-raf. Biochem. Pharmacol. 45, 1373-1386.

Bradford, M.M., 1976. A rapid and sensitive method for the quantisation of microgram quantities of protein utilizing the principle of protein-dye binding Anal. Biochem. 72, 248-254.

Chao, H.R., Wang, S.L., Lin, L.Y., Lee, W.J., Papke, O., 2007. Placental transfer of polychlorinated dibenzo-p-dioxins, dibenzofurans, and biphenyls in Taiwanese mothers in relation to menstrual cycle characteristics. Food Chem. Toxicol. 45, 259-265.

Chen, C.Y., Hamm, J.T., Hass, J.R., Birnbaum, L.S., 2001. Disposition of polychlorinated dibenzo-p-dioxins, dibenzofurans and non-ortho polychlorinated biphenyls in pregnant long evans rats and the transfer to offspring. Toxicol. Appl. Pharmacol. 173, 285-293.

Colombo, A., Bonfanti, P., Orsi, F., Camatini, M., 2003. Differential modulation of cytochrome P450 1A and P-glycoprotein expression by aryl hydrocarbon receptor agonists and thyroid hormone in Xenopus laevis liver and intestine. Aquat. Toxicol. 63, 173-186.

Cunnane, S., Armstrong, J.K., 1990. Long-chain fatty acid composition of materna liver lipids during pregnancy and lactation in the rat: comparison of triglyceride to phospholipids. J. Nutr. 120, 338-345.

Czekaj, P., Wiaderkiewicz, A., Florek, E., Wiaderkiewicz, R., 2005. Tobacco smokedependent changes in cytochrome P450 1A1, 1A2, and 2E1 protein expressions in fetuses, newborns, pregnant rats, and human placenta. Arch. Toxicol. 79, 1324.

DeJongh, J., Wondergem, F., Seinen, W., van den Berg, M., 1993. Toxicokinetic interactions between chlorinated aromatic hydrocarbons in the liver of the C57BL/6 J mouse: I. Polichlorinated biphenyls. Arch. Toxicol. 67, 453-460.

Dekoning, E.P., Karmaus, W., 2000. PCB exposure in utero and via breast milk. A review. J. Exp. Anal. Environ. Epidemiol. 10, 285-293.

Diliberto, JJ. Burgin, D.E., Birnbaum, L, 1999. Effects of CYP1A2 on disposition of 2 3, 7, 8-tetrachlorodibenzo-p-dioxin, 2, 3, 4, 7, 8-pentacholordibenzofuran and 2, $2^{\prime}, 4,4^{\prime}, 5,5^{\prime}$-hexachlorobyphenyl in CYP1A2 knockout and parental (C57BL/6N and $129 / \mathrm{Sv}$ ) strains of mice. Toxicol. Appl. Pharmacol. 159, 52-64.
Dragin, N., Dalton, T.P., Miller, M.L., Shertzer, H.G., Nebert, D.W., 2006. For dioxininduced birth defects, mouse or human CYP1A2 in maternal liver protects whereas mouse CYP1A1 and CYP1B1 are inconsequential. J. Biol. Chem. 281, $18591-18600$.

Fardel, O., Lecureur, V., Corlu, A., Guillozzo, A., 1996. P-glycoprotein induction in rat liver epithelial cells in response to acute 3-methylcholantrene treatment. Biochem. Pharmacol. 51, 1427-1436.

Gallenberg, L.A., Vodicnik, M.J., 1997. Potential mechanisms for redistribution of polychlorinated biphenyls during pregnancy and lactation. Xenobiotica 17, 299-310.

Koppe, J.G., Olie, K., van Wijnen, J., 1992. Placental transport of dioxins from mother to fetuses. II. PCBs, dioxins and furans and vitamin $\mathrm{K}$ metabolism. Dev. Pharmacol. Therapeut. 18, 9-13.

Kuriyama, N.S., Chahoud, I., 2004. In utero exposure to low-dose 2,3',4,4',5pentachlorobiphenyl (PCB118) impairs male fertility and alters neurobehavioral in rat offspring. Toxicology 202, 185-197.

Lyche, J.L., Skaare, J.U., Larsen, H.J.S., Ropstad, E., 2004. Levels of PCB126 and 153 in plasma and tissues in goats exposed during gestation and lactation. Chemosphere 55, 621-629.

Lin, J., Yamazaki, M., 2003. Role of P-glycoprotein in pharmacokinetics: clinical implications. Clin. Pharmacokinet. 42, 59-98.

McFarland, V., Clarke, J.U., 1989. Environmental occurrence, abundance, and potential toxicity of polychlorinated biphenyl congeners: considerations for a congener-specific analysis. Environ. Health Perspect. 81, 225-239.

Newland, M.C., 2001. Neurobehavioral toxicity of methylmercury and PCBs effectsprofiles and sensitive populations. Environ. Toxicol. Pharmacol. 12, 119-128.

Novotna, M., Libra, A., Kopecky, M., Pavek, P., Fendrich, Z., Semecky, V., Staud, F. 2004. P-glycoprotein expression and distribution in the rat during pregnancy. Reprod. Toxicol. 18, 785-792.

Omura, T., Sato, R., 1964. The carbon monoxide-binding pigment of liver microsomes. I. Evidence for its hemoprotein nature. J. Biol. Chem. 239, 23702378.

Pineau, T., Daujat, M., Pichard, L., Daujat, M., Pichard, L, Girard, F., Angevain, J., Bonfils, C., Maurel, P., 1991. Developmental expression of rabbit cytochrome P450 CYP 1A1, CYP 1A2 and CYP 3A6 genes. Effect of weaning and rifampicin. Eur. J. Biochem. 197, 145-153.

Pravettoni, A., Colciago, A., Negri-Cesi, P., Villa, S., Celotti, F., 2005. Ontogenetic development, sexual differentiation, and effects of Aroclor 1254 exposure of the arylhydrocarbon receptor and of the arylhydrocarbon receptor nuclear translocator in the rat hypothalamus. Reprod. Toxicol. 20, 521-530.

Skaare, J.U., Bernhoft, A., Derocher, A., Gabrielsen, G.W., Goksøyr, A., Henriksen, E., Larsen, H.J., Lie, E., Wiig, Ø., 2000. Organochlorines in top predators at Svalbardoccurrence, levels and effects. Toxicol. Lett. 112-113, 103-109.

Tampal, N.M., Robertson, L.W., Srinivasan, C., Ludewig, G., 2003. Polychlorinated biphenyls are not substrates for multidrug resistance transporter-1. Toxicol. Appl. Pharmacol. 187, 168-177.

Wakui, S., Yokoo, K., Takahashi, H., Muto, T., Suzuki, Y., Kanai, Y., Hano, H., Furusato, M., Endou, H., 2006. Prenatal 3,3',4,4',5-pentachlorobiphenyl exposure modulates induction of rat hepatic CYP $1 \mathrm{~A} 1,1 \mathrm{~B} 1$, and AhR by 7,12 dimethylbenz[ $\alpha]$ anthracene. Toxicol. Appl. Pharmacol. 210, 200-211.

Wang, S.L., Lin, CY., Leon Guo, Y., Lin, L.Y., Chou, W.L., Chang, L.W., 2004. Infant exposure to polychlorinated dibenzo-p-dioxins, dibenzofurans and biphenyls (PCDD/Fs, PCBs) correlation between prenatal and postnatal exposure. Chemosphere 54, 1459-1473. 